\title{
DDITORVI
}

\section{Research for development}

It is accepted the world over that science and technology are of fundamental importance in the socio-economic and cultural development of a country. Today, a wide gap exists in the levels of the practice and application of science and technology between the developed and developing countries of the world, which no doubt is an impediment to the development of the latter. We in the developing world must wake up to the reality that the science and technology gap is widening and it is vital to find suitable solutions to first minimize and then close this gap altogether. On an average, Sri Lanka spends only $0.18 \%$ of the gross domestic product on scientific and technological research and development. This is grossly inadequate and without delay this allocation for R\&D has to be increased.

We must recognize the changing context of scientific enterprise in responding to the national needs. This responsibility lies primarily with the rulers of the country who decide on the priorities and the planners and economists who advise the rulers along with entrepreneurs, educators and of course the scientists and technologists. The development of science and technology for the betterment of our people thus becomes a co-operative effort and will become a reality only if a suitable environment is created and promoted.

The message of science should reach all people of the country. There should be a strong partnership between the public and private sectors that must cooperate in research, development and application of science and technology for the welfare of the people. The scientists and technologists in universities, $R \& D$ institutions and other technological institutions bear the responsibility to engage in meaningful research that will generate the appropriate technology the country needs. To achieve this goal effectively, all R\&D institutions must be provided with autonomy and independence in decision making which is necessary for their smooth functioning. Such an environment will ensure that scientists and technologists achieve the desired results speedily.

The scientists while engaging in research the country needs must also share their findings with others through quality scientific publications. In doing so, there are many responsibilities they must adhere to. They must ensure that their results are accurate and inferences correct. Researchers must also respect intellectual property rights of other researchers. No claim should be made for authorship of a paper unless the scientist himself has contributed significantly to the conception and design of the research, directed, conducted, analyzed or interpreted relevant data and drafted or edited the paper critically before publication. Researchers must also be mindful to always acknowledge the contributions made by others who are not authors.

It must be emphasized that scientists and technologists must pay special attention to research and innovations in areas of relevance to the economy of the country, in addition to basic research. There is also the need to support mechanisms that enable the scaling up of research findings to the level of utilization and commercialization. In this manner, the findings of the researchers could be made use of and exploited in developing technologies needed for economic benefit.

It must be kept in mind that the above can be achieved only through the fullest appreciation by decision makers and planners that science and technology must permeate into policies and plans in all sectors and scientists and technologists too be involved in decision making. It should also be recognized that scientists and technologists have to play a vital role in the economic development of the country. 